04

\title{
Абляция кремния в воздухе моно- и бихроматическими импульсами лазерного излучения с длинами волн 355 и $532 \mathrm{~nm}$
}

\author{
(C) А.Н. Чумаков, В.В. Лычковский, И.С. Никончук, А.С. Мацукович
}

Институт физики им. Б.И. Степанова НАН Беларуси, 220072 Минск, Беларусь

e-mail: a.chumakov@dragon.bas-net.by

Поступило в Редакцию 2 июля 2021 г.

В окончательной редакции 3 сентября 2021 г.

Принято к публикации 8 сентября 2021 г.

Методами оптической и электронной сканирующей микроскопии, спектроскопии комбинационного рассеяния, профилометрии лазерных кратеров, а также видеорегистрации свечения плазменного факела во времени исследована абляция пластин кремния в воздухе при воздействии одиночных и сдвоенных наносекундных импульсов лазерного излучения с длинами волн 355 и $532 \mathrm{~nm}$. Установлена зависимость удельного выноса материала мишени от плотности мощности лазерного излучения и временного интервала между сдвоенными импульсами бихроматического лазерного излучения. Выявлено откольное разрушение кремния в широком диапазоне параметров облучения, и определены характеристики абляционных и откольных кратеров при бихроматическом лазерном воздействии.

Ключевые слова: наносекундная лазерная абляция, удельный вынос массы, модификация поверхности, динамика лазерной плазмы, образование кратера, откол.

DOI: $10.21883 /$ JTF.2022.01.51849.202-21

\section{Введение}

Исследования взаимодействия лазерного излучения с материалами и приповерхностной плазмой остаются актуальными в течение ряда десятилетий вследствие непрерывного развития лазеров и их технологических применений, а также из-за огромной сложности и нелинейности происходящих при этом процессов [14]. Многие технологические применения лазеров основаны на лазерной абляции материалов, т.е. на удалении вещества облучаемого образца в процессе воздействия на его поверхность лазерного излучения с достаточно высокой плотностью мощности, обеспечивающей локальное разрушение облучаемого материала с образованием приповерхностной плазмы и выносом мелкодисперсных частиц материала. Абляция и вынос материала с облучаемой поверхности образца в воздухе, как правило, усиливается с ростом плотности мощности воздействующего излучения и уменьшением длительности лазерных импульсов до тех пор, пока образующаяся приповерхностная плазма не начнет заметно экранировать мишень от лазерного излучения. Эффективность лазерной абляции зависит от оптических и теплофизических характеристик облучаемого материала, а также от длины волны, плотности мощности лазерного излучения и длительности лазерных импульсов [1-4].

В связи с широким использованием кремния в микроэлектронике лазерное воздействие на пластины кремния активно исследуется в последние годы для выявления эффективных режимов их обработки. Коэффициент поглощения кремния возрастает на три порядка с уменьшением длины волны излучения от 1064 до $266 \mathrm{~nm}$, поэтому повысить эффективность его обработки можно при использовании 2, 3 или 4 гармоники излучения $\mathrm{Nd}$ : YAG-лазера [5-8].

При наносекундном лазерном воздействии на кремний в воздухе с длиной волны излучения $266 \mathrm{~nm} \mathrm{c} \mathrm{ростом}$ плотности мощности излучения от 1 до $20 \mathrm{GW} / \mathrm{cm}^{2}$ наблюдается равномерный рост концентрации электронов и температуры плазмы, а также выноса массы [5]. Однако с повышением плотности мощности лазерного излучения (ЛИ) свыше $22 \mathrm{GW} / \mathrm{cm}^{2}$ обнаружен скачкообразный рост объема кратера и выброса частиц, а также резкое замедление роста концентрации электронов и температуры плазмы, что дало основание для рассмотрения взрывного кипения в качестве механизма выноса массы, обусловленного переходом перегретого кремния из состояния жидкого металла к жидкому диэлектрику, обладающему большей прозрачностью для воздействующего лазерного излучения [5,6].

Применение $\mathrm{Nd}$ :YAG-лазеров с диодной накачкой позволяет увеличить частоту повторения лазерных импульсов до сотен $\mathrm{kHz}$, что не только многократно ускоряет обработку кремния в режиме абляции [7,8], но и способствует образованию и разогреву абляционной плазмы, сводя к минимуму образование плазмы в воздухе, окружающем облучаемый образец [9].

При фемтосекундном лазерном воздействии на кремний с длиной волны ЛИ $\sim 800 \mathrm{~nm}$ и возрастающей плотностью энергии облучения выявлены окисление, аморфизация, рекристаллизация, испарение, абляция и образование периодических структур. Показано, что для абляции кремния в этих условиях необходимо достижение пороговой плотности энергии $\sim 0.2 \mathrm{~J} / \mathrm{cm}^{2}$, которая 
слабо зависит от длительности и количества лазерных импульсов [10].

В основе методов лазерной автоматизированной обработки кремния обычно лежит абляция под действием импульсно-периодического лазерного излучения с высокой частотой следования лазерных импульсов от 50 до $200 \mathrm{kHz}$ и с большой эллиптичностью пятна облучения в случае резки [7,8,10-12]. Для повышения эффективности резки кремниевых пластин на чипы часто используют лазерное управляемое термораскалывание (ЛУТ, „stealth dicing“"в англоязычной литературе), которое основано на образовании трещины вдоль траектории сканирования лазерного пучка при его острой фокусировке на образец, сопровождающейся быстрым локальным разогревом материала вследствие экспоненциального роста коэффициента поглощения лазерного излучения, а затем резким охлаждением струей хладагента [13-15].

Существенного повышения эффективности абляции материалов, разогрева абляционной плазмы и генерации ударных волн следует ожидать при воздействии сдвоенных импульсов лазерного излучения с регулируемым временным интервалом и порядком следования, особенно различающихся длиной волны излучения $[9,16,17]$.

Двухимпульсное бихроматическое лазерное воздействие дает больше степеней свободы для управления процессом лазерной абляции материалов, различающихся по теплофизическим и оптическим характеристикам, однако остается пока недостаточно исследованным. Цель настоящей работы состоит в определении особенностей лазерной абляции кремния в атмосферном воздухе при его облучении наносекундными импульсами монохроматического и бихроматического лазерного излучения с длинами волн 355 и $532 \mathrm{~nm}$ в широком диапазоне параметров, а также в выявлении режимов эффективного удельного выноса массы и образования приповерхностной плазмы.

\section{1. Экспериментальная установка и методы измерений}

Установка создана на основе двух $\mathrm{Nd}$ :YAG-лазеров LH-2132 и LH-2137 (ООО „ЛОТИС ТИИ“, Минск) и системы синхронизации, обеспечивающей генерацию парных наносекундных импульсов ЛИ с длинами волн 355 и $532 \mathrm{~nm}$ длительностью 18 и $15 \mathrm{~ns}$ соответственно, следующих с регулируемым временным интервалом между ними и управляемым порядком их следования. Форма временного профиля импульсов лазерного излучения регистрировалась фотоприемником 11HSP-V2 (Standa) на осциллографе Teledyne Lecroy Wave Surfer $510 \mathrm{R}$ с полосой пропускания $1 \mathrm{GHz}$. Энергия лазерных импульсов контролировалась прибором Ophir с измерительной головкой PE25BF-DIF-V2 ROHS. Соосный пучок излучения обоих лазеров формировался с помощью спектроделителя и фокусировался ахроматическим объективом $(f=150 \mathrm{~mm})$ на поверхности кремниевой пла- стины. В качестве мишеней использовались кремниевые пластины (111) толщиной от 180 до $375 \mu \mathrm{m}$.

Диаметры пятен лазерного облучения на мишени составляли $200 \mu \mathrm{m}$ для $\lambda=355 \mathrm{~nm} \quad$ и $250 \mu \mathrm{m}$ для $\lambda=532 \mathrm{~nm}$. Для повышения однородности пятен облучения использовались максимально возможные уровни накачки лазеров вместе с ослаблением энергии лазерных импульсов калиброванными светофильтрами. Исследования воздействия одноимпульсного монохроматического излучения проводились в интервале интенсивностей от 0.1 до $5 \mathrm{GW} / \mathrm{cm}^{2}$.

Поверхность облученных образцов исследовалась с помощью сканирующего электронного микроскопа TESCAN VEGA 3 (TESCAN, Чехия) и многофункционального комплекса „NanoFlex“ (Solar LS, Беларусь) на базе микроскопа, обеспечивающего возбуждение и регистрацию спектров комбинационного рассеяния (КРС) при фокусировке лазерного излучения с длиной волны $488 \mathrm{~nm}$ в пятно диаметром $100 \mu \mathrm{m}$.

Абляционный лазерный факел регистрировался видеокамерой [18] на основе ПЗС матрицы ICX415AL c объективом И-90У 4/75 ( $f=75 \mathrm{~mm})$. Видеокамера использовалась в режиме регистрации серии из 40 кадров с экспозицией отдельного кадра $\sim 3 \mathrm{~ms}$ и регулируемым моментом пуска камеры от системы синхронизации на основе генератора импульсов Г5-54, связанного с лазером. Это позволяло в определенной мере отслеживать динамику развития плазменного факела во времени. Временной интервал между лазерным импульсом и импульсом синхронизации видеокамеры контролировался осциллографом по сигналам от фотодиода и генератора импульсов соответственно.

Экспериментально удельный вынос массы определялся по объему сквозного отверстия в пластине кремния толщиной $180 \mu \mathrm{m}$, образуемого при воздействии счетного числа лазерных импульсов, с учетом известной плотности кремния $2.33 \mathrm{~g} / \mathrm{cm}^{3}$ и измеренной суммарной энергии лазерных импульсов. Удельный вынос массы при двухимпульсном бихроматическом воздействии на кремний определялся при различных временных интервалах следования импульсов излучения в диапазоне от -40 до $+40 \mu \mathrm{s}$ (отрицательное значение интервала соответствует опережающему воздействию коротковолнового лазерного импульса) с плотностями мощности в пятне облучения $q_{355}=1.9$ и $q_{532}=3.5 \mathrm{GW} / \mathrm{cm}^{2}$, выбор которых обоснован результатами исследований.

Профили лазерных кратеров на поверхности кремния регистрировались профилометром ACCRETECH Surfcom Crest DX-T с разрешением в $1 \mu \mathrm{m}$.

\section{2. Экспериментальные результаты и их обсуждение}

Облучение кремниевых пластин в воздухе 10 импульсами монохроматического лазерного излучения с длинами волн 355 и $532 \mathrm{~nm}$ и плотностью мощности 

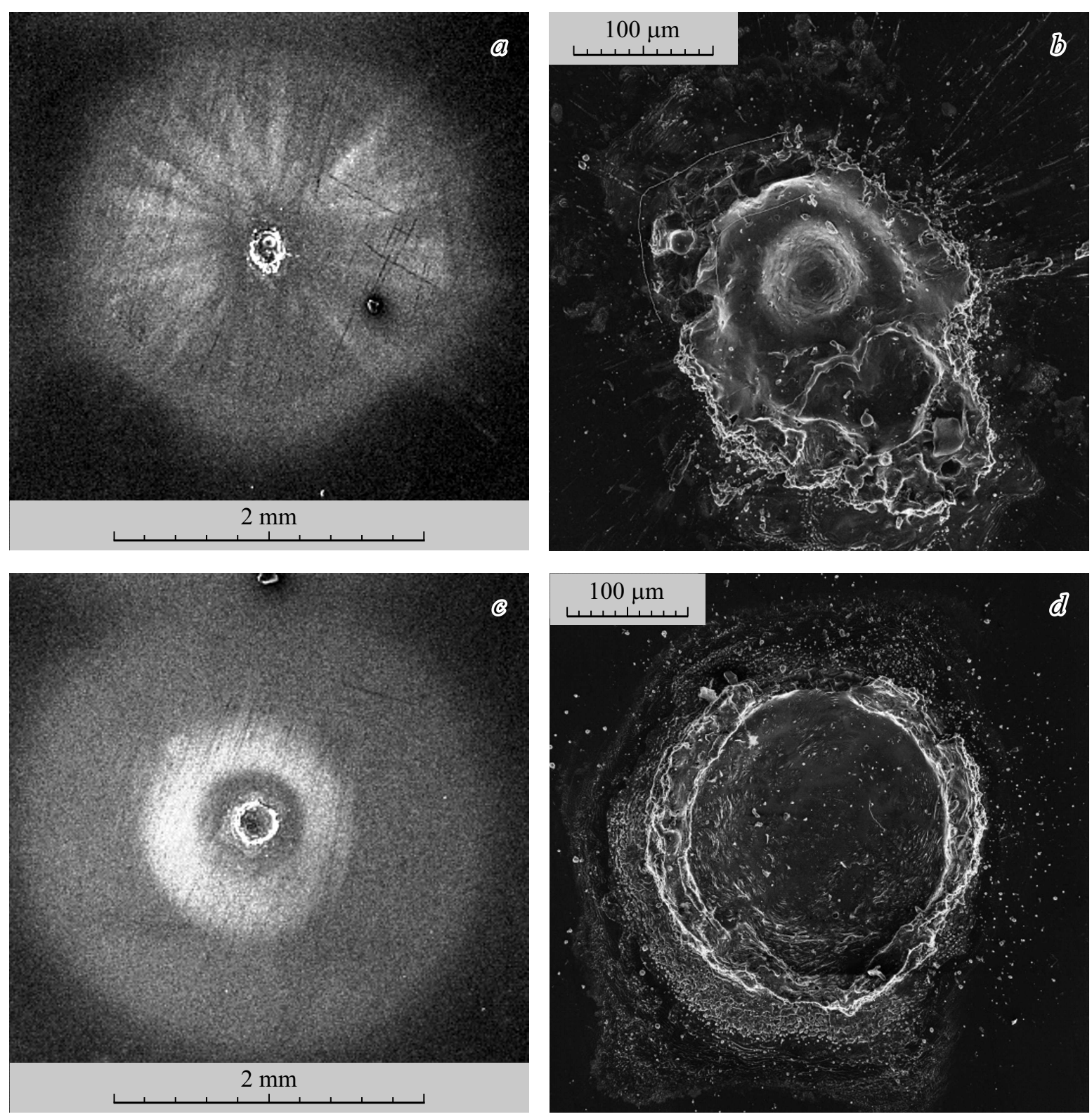

Рис. 1. СЭМ снимки образцов кремния после воздействия монохроматического лазерного излучения с длиной волны $355(a, b)$ и $532 \mathrm{~nm}(c, d)$ при плотности мощности излучения $q_{355}=2.16$ и $q_{532}=4.01 \mathrm{GW} / \mathrm{cm}^{2}$.

$q_{355}=2.16$ и $q_{532}=4.01 \mathrm{GW} / \mathrm{cm}^{2}$ приводит к формированию абляционных кратеров, окруженных ореолом (зоной модификации) диаметром до $2.5 \mathrm{~mm}$ со сложной структурой, которая отчетливо различается на снимках сканирующей электронной микроскопии (рис. 1).

При воздействии ЛИ с $\lambda=355 \mathrm{~nm}$ в области ореола формируются радиальные „лепестки“, образовавшиеся, вероятно, вследствие разлета микрочастиц в ходе абляции. На окраинах кратера наблюдается обильное количество застывшего расплава, формирующего борт кратера. Это позволяет говорить об обильном количестве расплава, образуемого в ходе абляции, и интенсивном его вымывании из кратера. Профиль кратера имеет ступенчатый вид. Следует отметить также образование микротрещин в области ореола кратера (рис. 1,a).

При воздействии ЛИ с $\lambda=532 \mathrm{~nm}$ образуется кратер округлой формы, ограниченный кольцеобразным бортом. Ореол кратера вне области абляции кремния состоит из кольцевых зон, обусловленных протеканием на поверхности образца процессов отжига, окисления и аморфизации (рис. $1, c, d)$.

При комбинированном лазерном воздействии на кремний десяти парных импульсов с длинами волн $\lambda=355$ и $532 \mathrm{~nm}$ (межимпульсный интервал $\Delta \tau=-1.4 \mu \mathrm{s}$, $q_{355}=2.16$ и $\left.q_{532}=3.76 \mathrm{GW} / \mathrm{cm}^{2}\right)$ также образуется кратер округлой формы, окруженный ореолом из ряда 

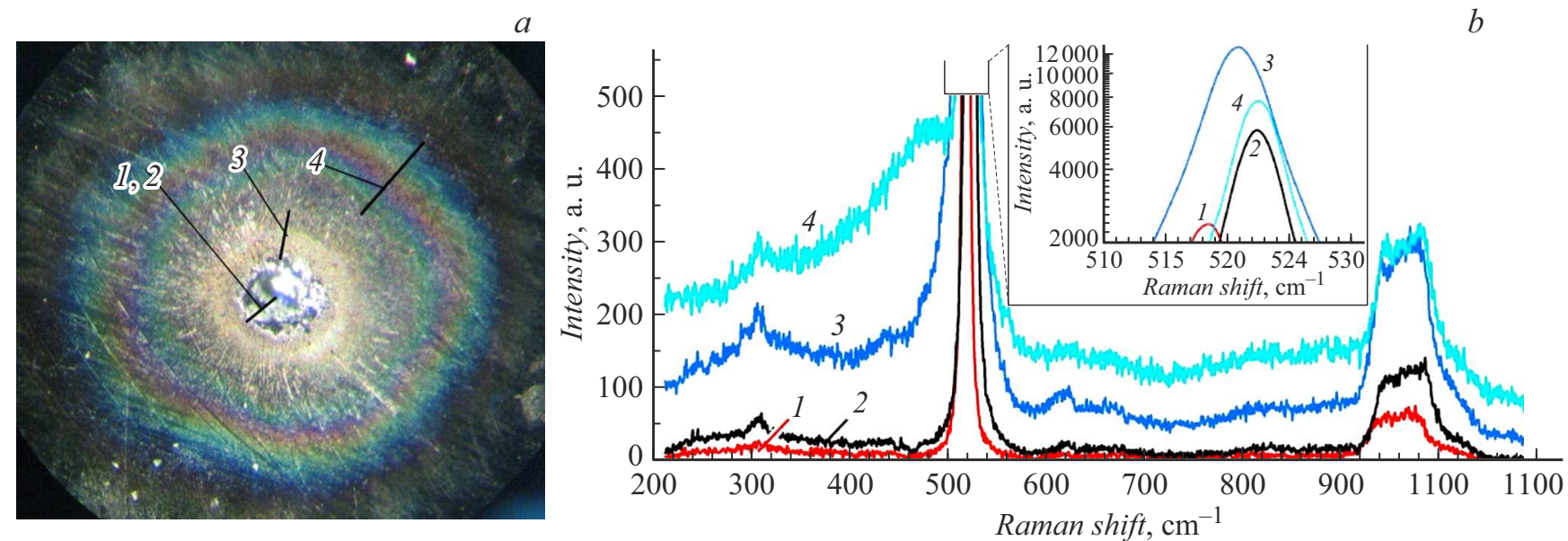

Pис. 2. Микрофотография облученного образца кремния $(a)$ и спектры КР различных зон в окрестности кратера $(b): 1-$ центр кратера, 2 - борт кратера, 3 - зона с желто-коричневыми микрочастицами, 4 - зона с радужной окраской (межимпульсный интервал $\Delta \tau=-1.4 \mu \mathrm{s}, q_{355}=2.16$ и $\left.q_{532}=3.76 \mathrm{GW} / \mathrm{cm}^{2}\right)$.

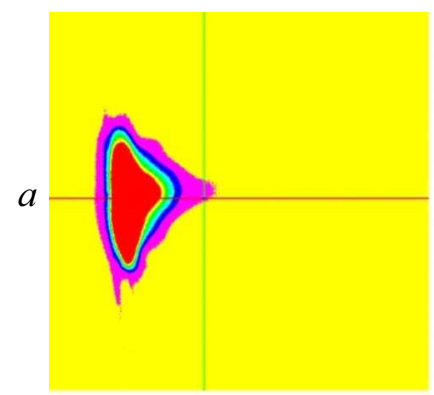

$N=1$

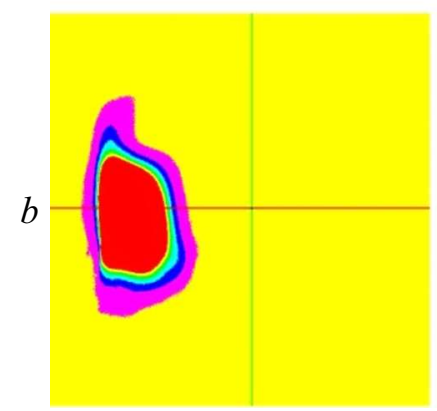

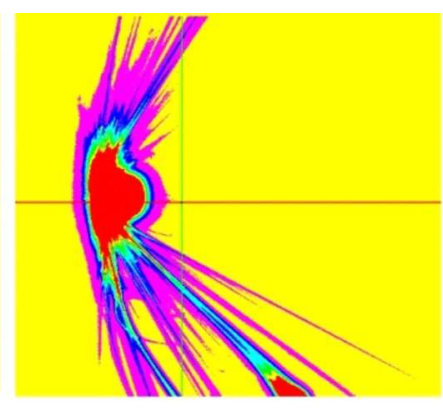

$N=15$

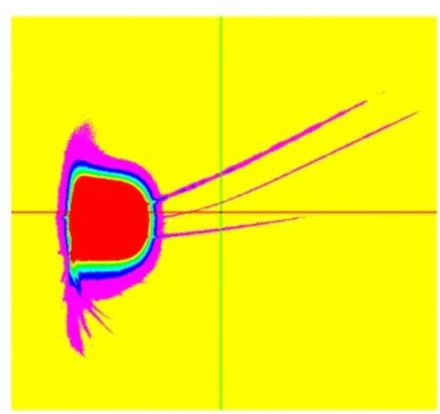

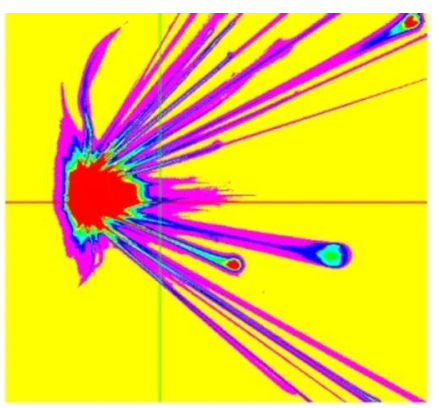

$N=25$

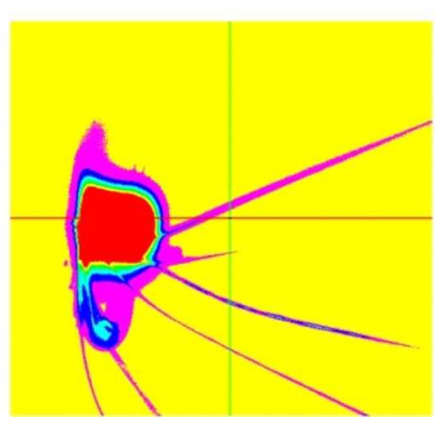

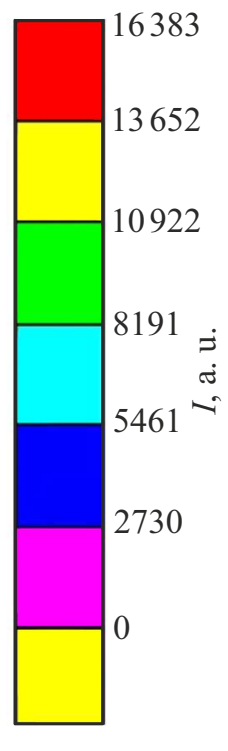

Рис. 3. Отдельные видеокадры плазменного факела при воздействии на кремний в воздухе 1,15 и 25 -го лазерных импульсов серии с длиной волны излучения $355(a)$ и $532 \mathrm{~nm}(b)$. Синхронизация - до начала воздействия импульсов ЛИ $(\Delta \tau=-4 \mu \mathrm{s})$.

кольцевых зон (рис. 2,a), несколько отличающихся от наблюдаемых при воздействии импульса ЛИ с длиной волны $532 \mathrm{~nm}$.

Примечательным является преобладание в кратере кристаллического кремния, что свидетельствует об удалении большей части продуктов абляции из кратера. Возникновение зоны 3 с желто-коричневыми микрочастицами наблюдалось только при воздействии импульсов монохроматического излучения с $\lambda=355 \mathrm{~nm}$ или парных импульсов бихроматического излучения, что может указывать на особенности распада приповерхностных плазменных образований в этих режимах. Аморфный слой кремния характеризуется малой толщиной. На это указывает доминирование основного пика $521 \mathrm{~cm}^{-1}$ в спектре КР зоны 4. Формирование слоя аморфного кремния может быть обусловлено процессами конденсации в расширяющемся приповерхностном плазменном образовании.

Результаты видеорегистрации плазменного факела во времени при воздействии серии импульсов монохроматического лазерного излучения (355 и $532 \mathrm{~nm})$ на кремний в воздухе представлены на рис. 3, 4. Сопоставление отдельных видеокадров плазменного факела для 1, 15 и 25-го лазерных импульсов серии показывает, что 


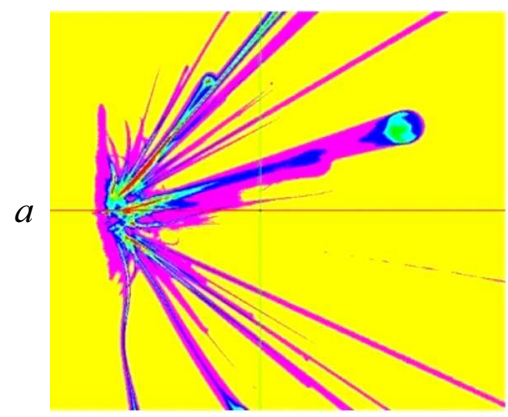

$\delta \tau=+0.6 \mu \mathrm{s}$

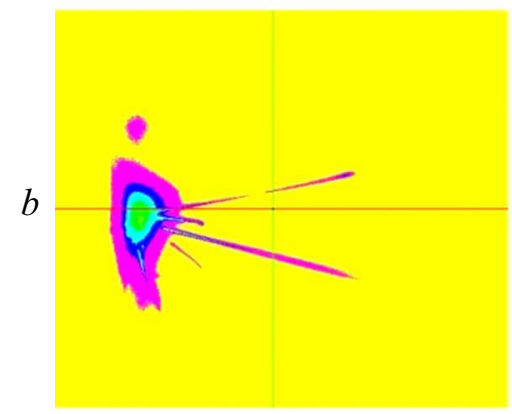

$\delta \tau=+8.8 \mu \mathrm{s}$

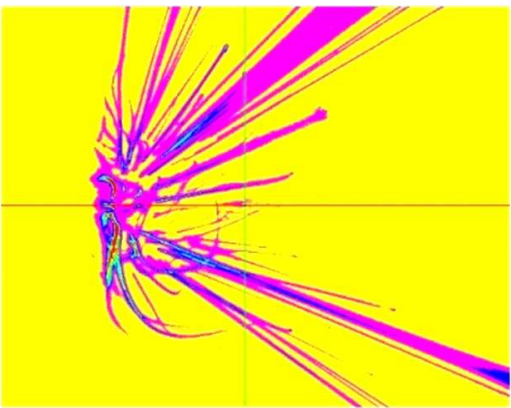

$\delta \tau=+25.7 \mu \mathrm{s}$

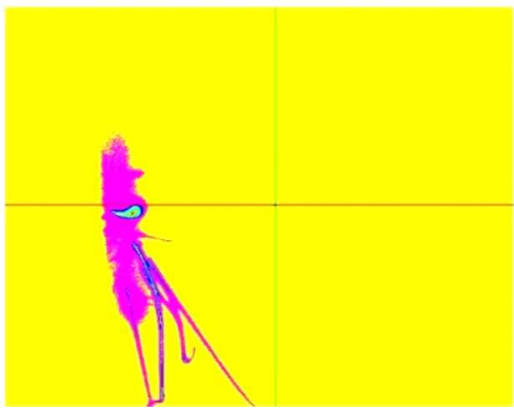

$\delta \tau=+22.8 \mu \mathrm{s}$

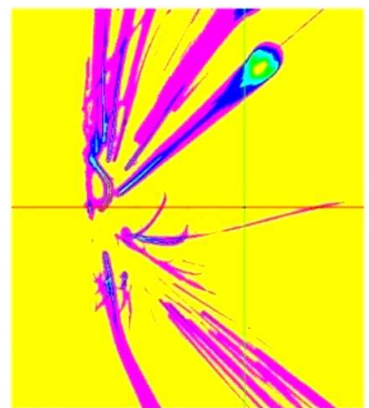

$\delta \tau=+51.5 \mu \mathrm{s}$

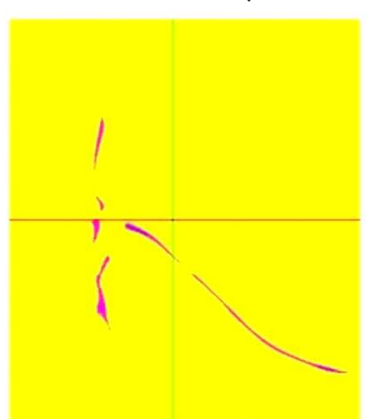

$\delta \tau=+33.8 \mu \mathrm{s}$

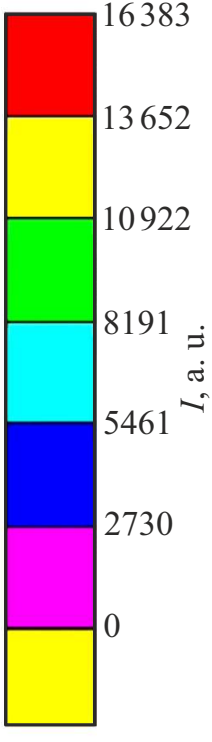

Рис. 4. Отдельные видеокадры свечения продуктов абляции с возрастающей временной задержкой после воздействия на кремний 15-го лазерного импульса серии с длиной волны излучения $355(a)$ и $532 \mathrm{~nm}(b)$.

при воздействии лазерных импульсов с длиной волны излучения $355 \mathrm{~nm}$ образование плазмы сопровождается интенсивным выбросом частиц конденсированной фазы в уменьшающийся телесный угол, что обусловлено быстрым углублением кратера с ростом числа воздействующих импульсов (рис. $3, a$ ).

Напротив, при воздействии лазерных импульсов с длиной волны излучения $532 \mathrm{~nm}$ форма плазменного факела мало меняется, выброс частиц конденсированной фазы слабо выражен и медленно нарастает с увеличением числа воздействующих импульсов (рис. $3, b$ ), что указывает на выраженный разогрев образующейся плазмы и малый рост глубины кратера. Вследствие вертикального расположения облучаемых пластин кремния в процессе воздействия серии лазерных импульсов наблюдается некоторый рост направленности треков частиц вниз (под действием силы тяжести). При воздействии ЛИ с длиной волны $355 \mathrm{~nm}$ и ростом количества импульсов форма кратера приближается к цилиндрической, а при воздействии излучения $532 \mathrm{~nm}-$ к сферической.

Анализ отдельных видеокадров свечения плазменного факела и продуктов абляции кремния с возрастающей временной задержкой после воздействия на кремний 15 го лазерного импульса серии (рис. 4) показал, что при воздействии импульса ЛИ $355 \mathrm{~nm}$ плазменный факел не регистрируется уже через $0.6 \mu \mathrm{s}$, тогда как при воздействии импульса ЛИ $532 \mathrm{~nm}$ факел регистрируется в течение $\sim 23 \mu$ s (рис. 4 ).
Интенсивный выброс частиц конденсированной фазы после воздействия 15 -го импульса лазерного излучения $355 \mathrm{~nm}$ продолжается в течение $\sim 50 \mu$ s (рис. 4, $a$ ). Кроме того, отдельные частицы, треки которых регистрируются на удалении от поверхности образца, фиксируются даже через $280 \mu$ s после воздействия лазерного импульса.

Выброс частиц конденсированной фазы после воздействия 15-го импульса лазерного излучения $532 \mathrm{~nm}$ несравненно слабее (рис. $4, b$ ). По мере затухания факела траектории частиц (треки) направляются преимущественно вниз (под действием силы тяжести). При этом через $34 \mu$ s регистрируются лишь отдельные частицы.

Наблюдаемые отличия в картине лазерной абляции кремния при воздействии лазерного излучения на указанных длинах волн обусловлены, прежде всего, многократным ростом (почти на 2 порядка) коэффициента поглощения кремния в облучаемых образцах с уменьшением длины волны воздействующего излучения от 532 до $355 \mathrm{~nm}$ [7].

Кроме того, коэффициент поглощения лазерного излучения в образующейся плазме квадратично зависит от длины волны, что приводит к его двукратному росту при переходе от излучения с $\lambda=355 \mathrm{~nm}$ к излучению c $\lambda=532 \mathrm{~nm}$.

Результаты исследования удельного выноса массы кремния в различных условиях воздействия импульсов монохроматического лазерного излучения, а также пар- 

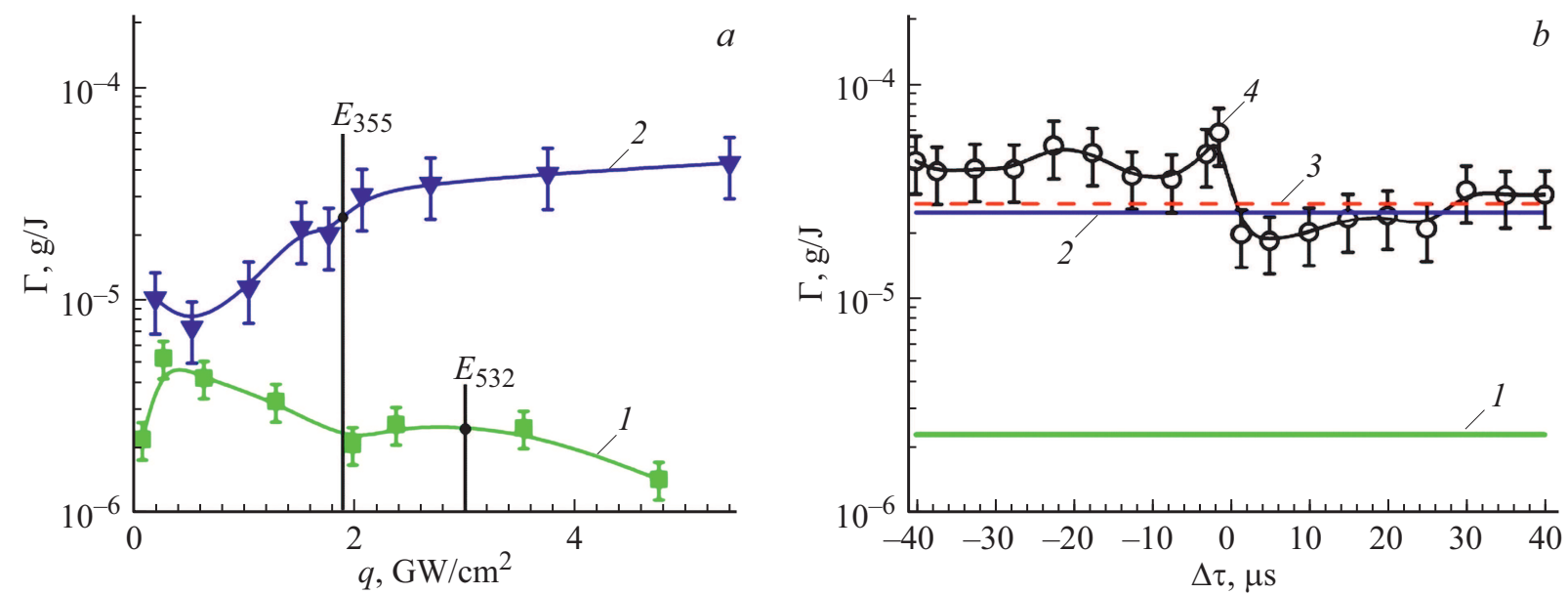

Рис. 5. Зависимость удельного выноса массы кремния: $a$ - от плотности мощности воздействующего (ЛИ) на длинах волн 532 (1) и $355 \mathrm{~nm}(2) ; b-$ от временного интервала бихроматических импульсов ЛИ с плотностью мощности $q_{355}=1.9$ и $q_{532}=3.5 \mathrm{GW} / \mathrm{cm}^{2}(1-\lambda=532,2-\lambda=355,3-$ оценка суммарного воздействия ЛИ на обеих длинах волн; $4-$ воздействие бихроматических импульсов ЛИ (отрицательные значения временного интервала соответствуют опережающему воздействию ЛИ $355 \mathrm{~nm})$.

ных импульсов бихроматического излучения с длинами волн 532 и $355 \mathrm{~nm}$ представлены на рис. 5.

Выполненные исследования выявили нелинейный характер зависимостей удельного выноса массы кремния от плотности мощности воздействующего монохроматического ЛИ с длинами волн 532 и $355 \mathrm{~nm}$ в интервале от 0.1 до $5 \mathrm{GW} / \mathrm{cm}^{2}$ (рис. $5, a$ ). Следует отметить, что абляция кремния обнаруживалась при пороговых значениях плотности энергии лазерного излучения $Q_{355} \sim 1.7 \mathrm{~J} / \mathrm{cm}^{2}$ и $Q_{532} \sim 2.5 \mathrm{~J} / \mathrm{cm}^{2}$ с длинами волн 355 и $532 \mathrm{~nm}$ соответственно. При воздействии ЛИ с длиной волны $532 \mathrm{~nm}$ удельный вынос массы (кривая 1 на рис. $5, a)$ достигает максимума $\sim 5 \cdot 10^{-6} \mathrm{~g} / \mathrm{J}$ при $q=0.3 \cdot 10^{9} \mathrm{~W} / \mathrm{cm}^{2}$, а при дальнейшем росте плотности мощности излучения до $5 \cdot 10^{9} \mathrm{~W} / \mathrm{cm}^{2}$ происходит нелинейный спад выноса массы до значения $\sim 1.5 \cdot 10^{-6} \mathrm{~g} / \mathrm{J}$, что указывает на развитие экранировки облучаемой поверхности продуктами абляции.

Напротив, при воздействии ЛИ с длиной волны $355 \mathrm{~nm}$ удельный вынос массы (кривая 2) уменьшается до минимума $\sim 7 \cdot 10^{-6} \mathrm{~g} / \mathrm{J}$ при $q=0.5 \cdot 10^{9} \mathrm{~W} / \mathrm{cm}^{2}$, а при дальнейшем росте плотности мощности излучения до $5 \cdot 10^{9} \mathrm{~W} / \mathrm{cm}^{2}$ вынос массы резко увеличивается до значения $\sim 4 \cdot 10^{-5} \mathrm{~g} / \mathrm{J}$ с последующим выходом на плато насыщения начиная с $q=2.8 \cdot 10^{9} \mathrm{~W} / \mathrm{cm}^{2}$. При этом формирование сквозного отверстия в пластине кремния на ее тыльной стороне характеризовалось признаками хрупкого разрушения с отколом отдельных фрагментов.

Выявленные различия зависимостей удельного выноса массы кремния от плотности мощности воздействующего излучения на исследуемых длинах волн соответствуют обнаруженным особенностям динамики плазменного факела (рис. 3,4). Так, при воздействии ЛИ $\lambda=355 \mathrm{~nm}$ на кремний наблюдается интенсивный выброс частиц конденсированной фазы, продолжающийся значительное время после распада плазменного факела, тогда как при воздействии ЛИ $\lambda=532 \mathrm{~nm}$ формируется ярко светящийся плазменный факел, а выброс частиц конденсированной фазы слабо выражен.

Интенсивный выброс частиц конденсированной фазы, вероятно, обусловлен высоким коэффициентом поглощения излучения $355 \mathrm{~nm}$ в кремнии, приводящим к образованию выраженного слоя жидкой фазы, удаляемого вместе с потоком плазмы с поверхности облучаемого образца.

Удельный вынос массы исследовался также при воздействии на кремний в воздухе сдвоенных бихроматических импульсов лазерного излучения на длинах волн 355 и $532 \mathrm{~nm}$ в зависимости от временного интервала и порядка следования комбинированных импульсов для ряда режимов. Типичная зависимость такого рода представлена на рис. 5, $b$. Такая зависимость также нелинейна. Удельный вынос массы 4 при опережающем воздействии коротковолнового излучения (в области отрицательных временных интервалов) превышает в 2-3 раза суммарный вынос 3 при монохроматическом воздействии на обеих длинах волн. Максимальные значения удельного выноса массы достигаются при межимпульсных интервалах $\Delta \tau=-20$ и $-1.3 \mu \mathrm{s}$. В области положительных временных интервалов между лазерными импульсами удельный вынос массы 4 в основном ниже суммарного 3 и лишь при интервалах от +30 до $+40 \mu$ s несколько превышает его.

Видеорегистрация плазменного факела при бихроматическом лазерном воздействии на кремний выполнялась в режимах, соответствующих экстремумам зависимости 4 удельного выноса массы на рис. 5, $b$. Эти режимы воздействия соответствовали значениям временного интервала между импульсами $\Delta \tau=-20,-1.4$, $+15,+30,+40 \mu \mathrm{s}$. Регистрация соответствующих ви- 
$a$

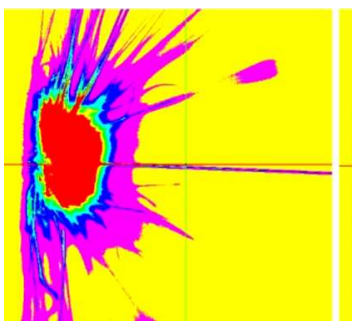

$b$

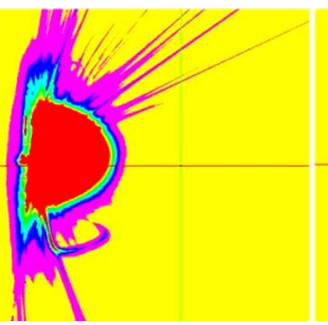

$c$

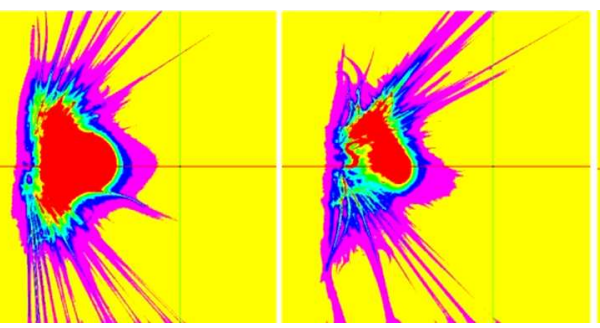

$d$

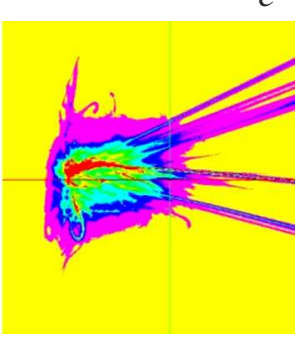

Рис. 6. Отдельные видеокадры свечения плазменного факела при бихроматическом лазерном воздействии $(\lambda=355,532 \mathrm{~nm})$ на пластину кремния с разным временным интервалом и порядком следования импульсов: $a-\Delta \tau=-20 ; b-\Delta \tau=-1.4 ; c-$ $\Delta \tau=+15 ; d-\Delta \tau=+30 ; e-\Delta \tau=+40 \mu$ s (отрицательные значения временного интервала соответствуют опережающему воздействию ЛИ $355 \mathrm{~nm}$, начало регистрации кадра соответствует второму импульсу пары).
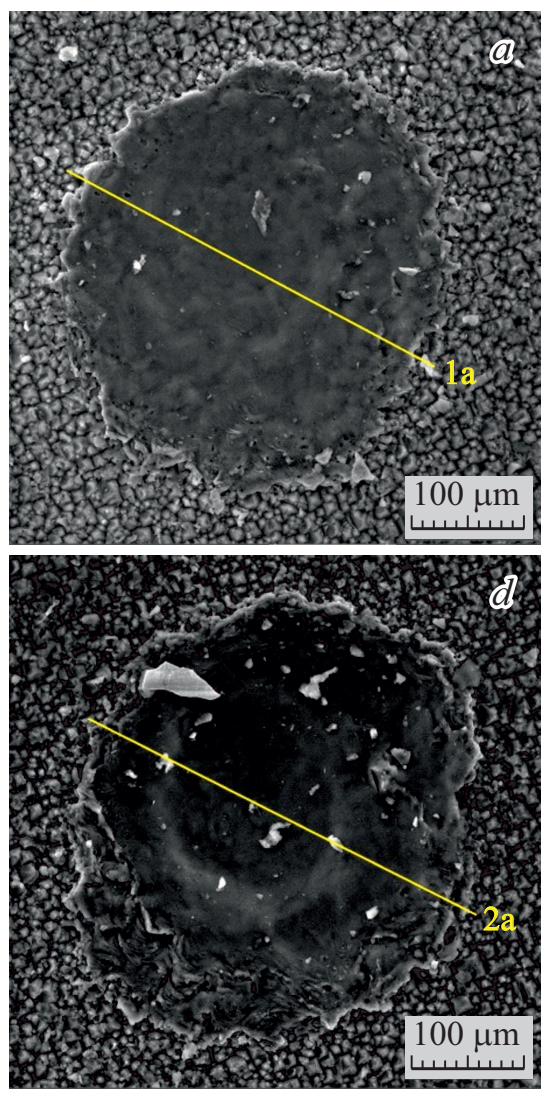
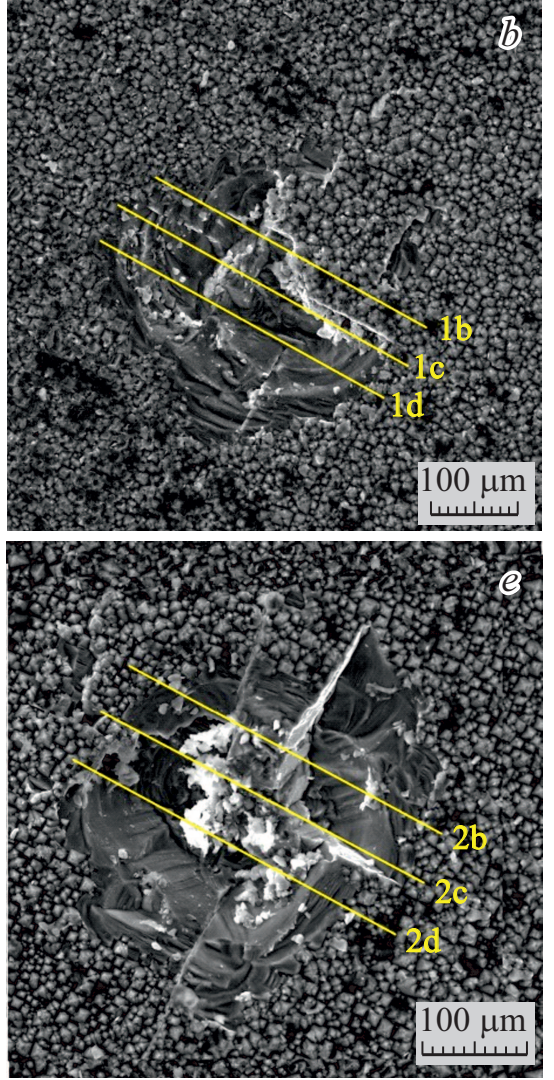
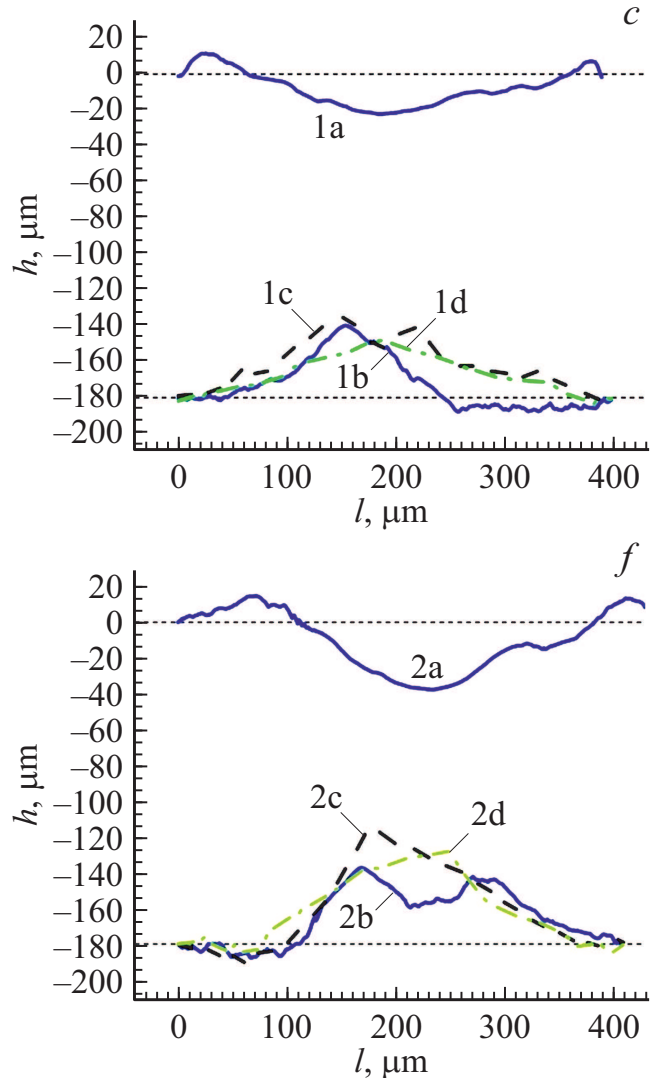

Рис. 7. СЭМ изображения абляционных $(a, d)$ и откольных $(b, e)$ кратеров, а также соответствующих профилей $(c, f)$, образованных в результате воздействия четырех $(a-c)$ и восьми пар $(d-f)$ импульсов лазерного излучения с длинами волн 355 и $532 \mathrm{~nm}$ (параметры воздействия: $q_{355}=1.9, q_{532}=3.5 \mathrm{GW} / \mathrm{cm}^{2}, \Delta \tau=-3 \mu \mathrm{s}$ ).

деокадров обеспечивалась необходимой синхронизацией видеокамеры от лазерной системы (рис. 6).

Для режима $\Delta \tau=-20 \mu \mathrm{s}$ с приходом 2-го лазерного импульса $(\lambda=532 \mathrm{~nm})$ регистрируется ярко светящийся факел приповерхностной плазмы и треки частиц (рис. 6,a), при этом количество и размер треков частиц значительно меньше по сравнению с монохроматическим воздействием $\lambda=355 \mathrm{~nm}$. Это может быть связано с испарением ряда частиц под действием излучения второго импульса пары $\lambda=532 \mathrm{~nm}$. С умень- шением временного интервала между импульсами пары до $\Delta \tau=-1.4 \mu \mathrm{s}$ (рис. $6, b)$ яркость и размеры факела приповерхностной плазмы существенно возрастают, а количество треков частиц уменьшается.

С изменением порядка следования лазерных импульсов пары (с переходом к положительным значениям временных интервалов $\Delta \tau=+15,+30,+40 \mu \mathrm{s}$ (рис. $6, c-e$ ) яркость и размеры факела приповерхностной плазмы уменьшаются, а количество треков частиц заметно возрастает, что свидетельствует о приближении картины 
абляции мишени к случаю воздействия импульса монохроматического излучения $\lambda=355 \mathrm{~nm}$.

Анализ сквозных отверстий в пластинах кремния, полученных при воздействии серии парных импульсов бихроматического излучения, выявил признаки откольного разрушения на тыльной стороне облучаемых пластин [22]. Явление откола часто исследуется с целью получения данных о прочности многих материалов $[23,24]$. Откольное разрушение монокристаллического кремния при воздействии наносекундных импульсов лазерного излучения с длиной волны $355 \mathrm{~nm}$ исследовалось в работе [25]. Авторами было показано, что порог откольного разрушения при сквозном сверлении линейно зависит от толщины пластин кремния и составляет $\sim 6.5 \mathrm{GW} / \mathrm{cm}^{2}$ для пластины толщиной $225 \mu \mathrm{m}$.

В связи с этим было предпринято детальное исследование абляционных кратеров на лицевой стороне пластин кремния и откольных кратеров на их тыльной стороне методами электронной микроскопии и профилометрии. При облучении пластины кремния толщиной $180 \mu \mathrm{m}$ серией импульсов ЛИ $\lambda=355 \mathrm{~nm}$ с плотностью мощности $1.5 \mathrm{GW} / \mathrm{cm}^{2}$ начальное формирование откольного разрушения на тыльной стороне пластины наблюдалось только после воздействия $\sim 10$ импульсов еще до образования в ней сквозного отверстия. Такая плотность мощности воздействующего лазерного излучения соответствует области резкого роста удельного выноса массы 2 на рис. 5, $a$.

В режиме бихроматического лазерного воздействия на пластины кремния параметры абляционных и откольных кратеров были исследованы при плотности мощности излучения $q_{355}=1.9 \mathrm{GW} / \mathrm{cm}^{2}$ и $q_{532}=3.5 \mathrm{GW} / \mathrm{cm}^{2}$ и временном интервале импульсов $\Delta \tau=-3 \mu \mathrm{s}$ (рис. 7).

Эксперименты показали, что воздействие двух пар бихроматических лазерных импульсов не приводило к откольному разрушению на тыльной стороне пластины кремния. В таких условиях облучения откол был выявлен только при воздействии четырех и более пар бихроматических лазерных импульсов. Типичные СЭМ снимки абляционного и откольного кратеров представлены на рис. 7 при воздействии четырех (рис. 7, $a, b$ ) и восьми (рис. $7, d, e$ ) пар импульсов вместе с результатами измерений их профилей (рис. 7,c,f).

Обращает на себя внимание отличие в форме абляционных и откольных кратеров. Абляционные кратеры характеризуются формой приближающейся к шаровому сегменту, а откольные кратеры характеризуются нерегулярной формой, образуемой несколькими частичными сколами, с приближенно треугольным профилем. Следует отметить, что максимальная глубина откольных кратеров превышает глубину абляционных в 1.5-2 раза. Это указывает на существенный вклад откола в удельный вынос массы при формировании сквозных отверстий в указанных режимах воздействия (рис. $5, b$ ).

\section{Заключение}

Экспериментально исследована абляция пластин кремния в воздухе при воздействии монохроматических и бихроматических лазерных импульсов с плотностью мощности от 0.1 до $5.0 \mathrm{GW} / \mathrm{cm}^{2}$ и длинами волн излучения 355 и $532 \mathrm{~nm}$. Установлен нелинейный рост удельного выноса массы кремния от $\sim 7 \cdot 10^{-6}$ до $4 \cdot 10^{-5} \mathrm{~g} / \mathrm{J}$ с ростом до $5 \cdot 10^{9} \mathrm{~W} / \mathrm{cm}^{2}$ плотности мощности лазерного излучения с длиной волны $355 \mathrm{~nm}$, тогда как для излучения $532 \mathrm{~nm}$ выявлен нелинейный спад удельного выноса массы от $\sim 5 \cdot 10^{-6} \mathrm{~g} / \mathrm{J}$ (при $q=0.3 \cdot 10^{9} \mathrm{~W} / \mathrm{cm}^{2}$ ) до значения $\sim 1.5 \cdot 10^{-6} \mathrm{~g} / \mathrm{J}$ при $q=5 \cdot 10^{9} \mathrm{~W} / \mathrm{cm}^{2}$. При этом воздействие лазерного излучения с длиной волны $355 \mathrm{~nm}$ сопровождается образованием плазменного факела с множественным выбросом частиц конденсированной дисперсной фазы, тогда как при воздействии излучения с длиной волны $532 \mathrm{~nm}$ формируется развитый плазменный факел с незначительным количеством частиц дисперсной фазы, что подтверждено данными видеорегистрации. Вокруг лазерного кратера на поверхности кремния формируется область модификации диаметром $\sim 2.5 \mathrm{~mm}$, структура и состав которой зависят от плотности мощности, длины волны лазерного излучения и временных параметров лазерных импульсов.

Максимальный удельный вынос массы кремния реализуется при воздействии сдвоенных импульсов бихроматического лазерного излучения с длинами волн 355 и $532 \mathrm{~nm}$ при опережающем следовании коротковолнового излучения, который зависит от плотности мощности излучения и временного интервала между импульсами и превышает в 2-3 раза суммарный вынос при монохроматическом воздействии, достигая максимумов при межимпульсных интервалах $\Delta \tau=-20$ и $-1.3 \mu \mathrm{s}$. В этих условиях формируется также наиболее развитый и яркий плазменный факел, что указывает на его значительный разогрев воздействующим лазерным излучением.

Выявлено откольное разрушение на тыльной стороне пластины кремния при воздействии серии 10-15 импульсов лазерного излучения $355 \mathrm{~nm}$ с плотностью мощности $1.5 \mathrm{GW} / \mathrm{cm}^{2}$ еще до образования в пластине сквозного отверстия. Определены характеристики абляционных и откольных кратеров при воздействии сдвоенных импульсов бихроматического лазерного излучения. Установлен существенный вклад откола в удельный вынос массы при формировании сквозных отверстий в режимах бихроматического лазерного воздействия.

\section{Финансирование}

Работа поддержана Государственной программой научных исследований Беларуси „Конвергенция - 2025“ (подпрограмма „Микромир, плазма и Вселенная“"). 


\section{Конфликт интересов}

Авторы заявляют, что у них нет конфликта интересов.

\section{Список литературы}

[1] С.И. Анисимов, Я.А. Имас, Г.С. Романов, Ю.В. Ходыко. Действие излучения большой мощности на металль (Наука, М., 1970)

[2] Дж. Рэди. Действие мощного лазерного излучения (Мир, М., 1974)

[3] У. Дьюли. Лазерная технология и анализ материалов (Мир, М., 1986)

[4] М.Н. Либенсон, Е.Б. Яковлев, Г.Д. Шандыбина. Взаимодействие лазерного излучения с веществом (силовая оптика). Часть II. Лазерный нагрев и разрушение материалов (НИУ ИТМО, СПб, 2014)

[5] H.C. Liu, X.L. Mao, J.H. Yoo, R.E. Russo. Spectrochim. Acta, Part B, 54 (11), 1607 (1999). DOI: $10.1016 / \mathrm{S} 0584-8547(99) 00092-0$

[6] J.H. Yoo, S.H. Jeong, R. Greif, R.E. Russo. J. Appl. Phys., 88 (3), 1638 (2000). DOI: 10.1063/1.373865

[7] M. Panzner, J. Kasper, H. Wust, U. Klotzbach, E. Beyer. Proc. SPIE, 4637, 496 (2002). DOI: 10.1117/12.470659

[8] H. Pantsar, H. Herfurth, S. Heinemann, P. Laakso, R. Penttila, Y. Liu, G. Newaz. In: 27th International Congress on Applications of Lasers \& Electro-Optics (Temecula California, ALIA, 2008), p. 278. DOI: 10.2351/1.5061387

[9] Л.Я. Минько, А.Н. Чумаков, Н.А. Босак. Квант. электрон., 17 (11), 1480 (1990). DOI: 10.1070/QE1990v020n11ABEH007540

[10] J. Bonse, S. Baudach, J. Krüger, W. Kautek, M. Lenzner. Appl. Phys. A, 74, 19 (2002). DOI: 10.1007/s003390100893

[11] J.M. Bovatsek, R.S. Patel. Proc. SPIE, 7585, 75850K (2010). DOI: $10.1117 / 12.845298$

[12] G. Galasso, M. Kaltenbacher, A. Tomaselli, D. Scarpa. J. Appl. Phys., 117 (12), 123101 (2015). DOI: 10.1063/1.4915118

[13] В.С. Кондратенко. Способ резки хрупких материалов : патент РФ № 2024441, МКИ5 СО3 В 33/02. 1991.

[14] T. Monodane, E. Ohmura, F. Fukuyo, K. Fukumitsu, H. Morita, Y. Hirata. JLMN, 1 (3), 231 (2006). DOI: $10.2961 / \mathrm{j} \mathrm{lmn} .2006 .03 .0016$

[15] В.С. Кондратенко, А.С. Наумов. Вестник МГТУ МИРЭА, 2 (3(8)), 1 (2015).

[16] A.N. Chumakov, N.A. Bosak, P.I. Verenich. High Temp. Mater. Processes, 18 (4), 269 (2014). DOI: 10.1615/HighTempMatProc.2015015608

[17] А.Н. Чумаков, Н.А. Босак, А.В. Панина. ЖПС, 84 (4), 595 (2017). [A.N. Chumakov, N.A. Bosak, A.V. Panina. J. Appl. Spectr., 84, 620 (2017). DOI: 10.1007/s10812-017-0519-y]

[18] I.S. Nikonchuk, A.N. Chumakov. J. Phys.: Conf. Ser., 666, 012021 (2016). DOI: 10.1088/1742-6596/666/1/012021

[19] P.G. Spizzirri, J.H. Fang, S. Rubanov, E. Gauja, S. arXiv:1002.2692 [cond-mat.mtrl-sci] (Cornell University, NY.)

[20] T.P. Nguyen, S. Lefrant. Solid St. Commun., 57 (4), 235 (1986). DOI: 10.1016/0038-1098(86)90146-8

[21] В.С. Левицкий, канд. дисс. (СПб, СПб гос. электротех. унет „ЛЭТИ“ им. В.И. Ульянова (Ленина), 2016)
[22] В.В. Лычковский, А.Н. Чумаков. В сб: Международная школа-конференция „Современные проблемы физики“, под ред. И.С. Никончук, М.С. Усаченка (Ин-т физики НАН Беларуси, Минск, 2020), с. 37-38.

[23] Я.Б. Зельдович, Ю.П. Райзер. Физика ударных волн и высокотемпературных гидродинамических явлений (Наука, М., 1966)

[24] С.А. Абросимов, А.П. Бажулин, В.В. Воронов, А.А. Гераськин, И.К. Красюк, П.П. Пашинин, А.Ю. Семенов, И.А. Стучебрюхов, К.В. Хищенко, В.Е. Фортов. Квант. электрон., 43 (3), 246 (2013). [S.A. Abrosimov, A.P. Bazhulin, V.V. Voronov, A.A. Geras'kin, I.K. Krasyuk, P.P. Pashinin, A.Yu. Semenov, I.A. Stuchebryukhov, K.V. Khishchenko, V.E. Fortov. Quant. Electron., 43 (3), 246 (2013). DOI: 10.1070/QE2013v043n03ABEH015106]

[25] J. Ren, S.S. Orlov, L. Hesselink. J. Appl. Phys., 97, 104304 (2005). DOI: 10.1063/1.1896095 